\title{
Marketing Digital em Redes Sociais e E-Commerce: Um Estudo Sobre o Impacto das Campanhas das Empresas de Banda Larga na Região do Cariri
}

\author{
Francisco Jurandir Ferreira ${ }^{1}$; Francisco Demontiez Dias Júnior ${ }^{2}$
}

\begin{abstract}
Resumo: O cenário econômico tem mudado muito nos últimos tempos, levando as empresas a buscarem meios inovadores para continuarem competitivas. Neste contexto, a pesquisa mostra a importância de as empresas entender que para o seu desenvolvimento e obtenção de resultados, precisam estar conectadas com os seus clientes. Assim, o presente trabalho, por meio de uma revisão de literatura e uma pesquisa quantitativa teve como objetivo analisar o impacto que as campanhas de marketing digital via redes sociais e e-commerce, praticadas pelas empresas de banda larga na região do Cariri, por meio de uma questionário aplicado online contendo 16 questões de múltipla escolha, onde foi obteve-se uma amostra de 244 pessoas. A pesquisa apresentou a importância do uso do marketing digital $e$-commerce, para a empresas do segmento, identificou que o público que mais utiliza o serviço da banda larga está entre os 18 e 30 anos, o meio mais utilizado pelas empresas para entrar em contato com cliente é telefone, percebe-se necessidade de novos meio de comunicação entre operadoras e consumidores estabelecendo o marketing de relacionamento. Os estudos foram concluídos alcançando o objetivo proposto, analisando o impacto das campanhas de marketing digital e e-commerce das operadoras de banda larga entre os consumidores de serviços de empresas de telecomunicação e banda larga da região do Cariri.
\end{abstract}

Palavras Chave: Competitividade; Relacionamento; Marketing Digital.

\section{Digital Marketing in Social Media and E-Commerce: A Study on the Impact of Broadband Companies Campaigns in the Cariri Region}

\begin{abstract}
The economic landscape has changed a lot in recent times, prompting companies to look for innovative ways to stay competitive. In this context, the research shows the importance of companies understanding that, for their development and results, they need to be connected with their customers. Thus, the present work, through a bibliographic review and quantitative research, aimed to analyze the impact of digital marketing campaigns via social networks and e-commerce, practiced by broadband companies in the Cariri region, through an online questionnaire containing 16 questions of choice, where a sample of 244 people was obtained. The research presented the importance of the use of e-commerce digital marketing, for companies in the segment, identified that the public that uses the broadband service is between 18 and 30 years, the medium most used by companies to get in touch with the customer is a telephone, it is necessary to have new means of communication between operators and consumers, establishing relationship marketing. The studies were concluded reaching the proposed objective, analyzing the impact of the digital marketing and e-commerce campaigns of broadband operators among consumers of services of telecommunications and broadband companies in the Cariri region.
\end{abstract}

Keywords: Competitiveness; Relationship; Digital Marketing.

\footnotetext{
${ }^{1}$ Centro Universitário Doutor Leão Sampaio. Contato: jurandirferreira.adm@gmail.com;

${ }^{2}$ Professor do Centro Universitário Leão Sampaio. Mestre em Administração pelo Programa de Pós Graduação em Administração da Universidade Federal de Pernambuco. Bacharel em Administração na Universidade Federal de Campina Grande.
} 


\section{Introdução}

Nos últimos anos, foi possível presenciar a inclusão das tecnologias digitais no cotidiano das pessoas, onde esta mudança comportamental e os avanços na área da tecnologia permitiram que a internet ganhasse espaço como ferramenta estratégica no ambiente empresarial, que com a evolução da internet possibilitou o desenvolvimento de novos negócios.

Segundo Zenone (2010) é essencial que as empresas tracem estratégias definidas quanto ao modo como realiza os seus atendimentos em nível global. Para tanto se faz necessário que se busque informações relevantes sobre o mercado e público alvo, desenvolvendo assim ações de marketing que possam trazer resultados satisfatórios para a empresa.

Dentre as ações de marketing, apontadas pelo autor acima, há um crescente cenário com grandes possibilidades de divulgação, que é o marketing digital, que tem como exemplo de ferramentas as redes sociais e o comércio pelo meio eletrônico. Por meio de tais, é possível encontrar muitas ferramentas que contribuem não somente com a divulgação, mas também com o gerenciamento do anúncio, propiciando conhecer de forma plena o público alvo.

Nota-se que na região do Cariri, há atualmente várias empresas que atuam no ramo de oferta de serviço de internet em banda larga, oferecendo seus serviços em planos de internet diversificados via fibra óptica, ADSL e rádio, com atrativos adicionais como telefonia fixa e TV por assinatura, criandose assim grande competitividade. Deste modo, entende-se que a criação de uma estratégia de marketing digital eficaz, seria um diferencial para a empresa que pode se destacar neste mercado.

No que se refere a problemática do presente trabalho, pode-se mencionar que a divulgação para grandes massas sempre foi um privilégio de grandes empresas, pois o custo sempre foi alto, restando a pequena empresa investir em propagandas de rádio ou panfletagem, que alcançava um público mais local e em menor número. Porém com o desenvolvimento da internet, mídias digitais e redes sociais, esse cenário mudou, fazendo com que a comunicação pudesse ser mais ágil e abrangente (POWELL, 2010).

Assim a pergunta problema deste trabalho foi: Qual o impacto as campanhas de marketing digital via redes sociais e e-commerce, praticadas pelas empresas de banda larga na região do Cariri, podem causar na decisão de compra dos consumidores?

Desta feita, o objetivo do presente artigo é analisar o impacto que as campanhas de marketing digital via redes sociais e e-commerce, praticadas pelas empresas de banda larga na região do Cariri, podem causar na decisão de compra dos consumidores. Para tanto, teve-se a pretensão de alcançar os seguintes objetivos específicos: apresentar as principais empresas que vendem o serviço de banda larga na cidade; conceituar o marketing digital e apresentar suas principais características; analisar o impacto 
das redes sociais e e-commerce, nas vendas de serviço de banda larga, bem como sua capacidade de divulgação.

Quanto a justificativa da presente pesquisa, pode-se mencionar que, com as transformações ocorridas na sociedade a internet e as redes sociais obtiveram um crescimento enorme e se tornaram uma grande e valiosa oportunidade de negócio. Além disso, o e-commerce passou a ser um valioso meio de vendas. Isto sinaliza a importância desta nova comunicação, que juntamente com o surgimento da economia digital o mundo passou a processar as informações de uma forma mais rápida, eficaz e com custo reduzido (ALBERTIN, 2010).

Justifica-se também por questões sociais, uma vez que, o empreendedorismo tem sido uma grande oportunidade de geração de emprego e renda. Assim, conseguir divulgar um produto com custos baixos e com eficácia, amplia as possibilidades de negócios na pequena empresa.

Assim, podemos perceber que esta nova forma de comunicação vem se tornando essencial para o mundo corporativo. Isto se dá principalmente devido ao grande mercado concorrido e competitivo, onde a divulgação eficaz e o uso consciente de recursos faz toda a diferença no que se refere a longevidade e permanência no cenário capitalista..

\section{Referencial Teórico}

\section{Histórico e Crescimento da Internet}

De acordo com Albertin (2010) a ideia da internet, criada em 1969, era utilizá-la como um sistema de comunicação, principalmente com finalidades militares, pela Advanced Research Projects Agency (Arpa), que faz parte do Departamento de Defesa Americano; assim, os sites de pesquisa da Arpa passaram a compartilhar informação e dar acesso a computadores de qualquer lugar.

Denominada como Arpanet, a ideia era ligar pontos considerados estratégicos para o país, como base militares e centros de pesquisa e de tecnologia, e impossibilitar a destruição da rede por possíveis ataques dos países inimigos, visto que o contexto mundial se apresentava sob a tensão da Guerra Fria (ALBERTINI, 2010).

Conforme Albertin (2010), atualmente, pode-se dizer que a internet é um sistema que distribui informações para os mais diversos países. Sua infraestrutura, em banda larga, possui capacidade para atingir, além de aplicações tecnológicas da informação, outros setores ligados a compras, prestação de serviço e mensagens como e-mail, publicação de informação e meios de contatos tais como a videoconferência. 
O crescimento deste ambiente digital, também chamado de grande teia mundial, ocorreu de forma acelerada e mantém-se em contínua evolução, tanto em número de usuários, como também em possibilidades que se refere à obtenção e oferta de entretenimento, cultura e informação, ampliação de relacionamentos e, principalmente, para realização de negócios (TURCHI, 2010).

A Empresa Brasileira de Telefonia, EMBRATEL, como sistema experimental, em 1994, lançou o serviço buscando entender melhor como funcionava a internet. Um ano depois, o Ministério das Telecomunicações, juntamente com o Ministério da Ciência e Tecnologia, uniu forças para tornar conhecida a internet além do âmbito educacional, de modo que as empresas passaram a explorá-la. Assim, o Brasil obteve uma verdadeira expansão na utilização da internet. A partir de então, a Rede Nacional de Pesquisa redefiniu seu papel, deixando de disponibilizar o backbone apenas para o meio acadêmico, para estender seus serviços de acesso a todos os setores da sociedade (TURCHI, 2012).

Segundo o IBGE (2018), o celular continua a ser o principal aparelho para acessar a internet no Brasil. Em 2016, o eletrônico era usado por 94,6\% dos internautas, à frente de computadores $(63,7 \%)$, tablets $(16,4 \%)$ e televisões $(11,3 \%)$. Onde $77,1 \%$ dos brasileiros possuíam algum celular, sendo grande número de smartphones com acesso à internet.

Conforme Ibope (2015), em pouco tempo, a internet se expandiu, passando de 100 mil usuários, em 1996, para um milhão de pessoas, em 1998. No período de 17 anos o crescimento da rede no Brasil se intensificou, alcançando a marca de 102,1 milhões de usuários em 2015, de acordo com o que pode ser visto no gráfico 1.

Gráfico 1. Crescimento do número de usuários de internet no Brasil.

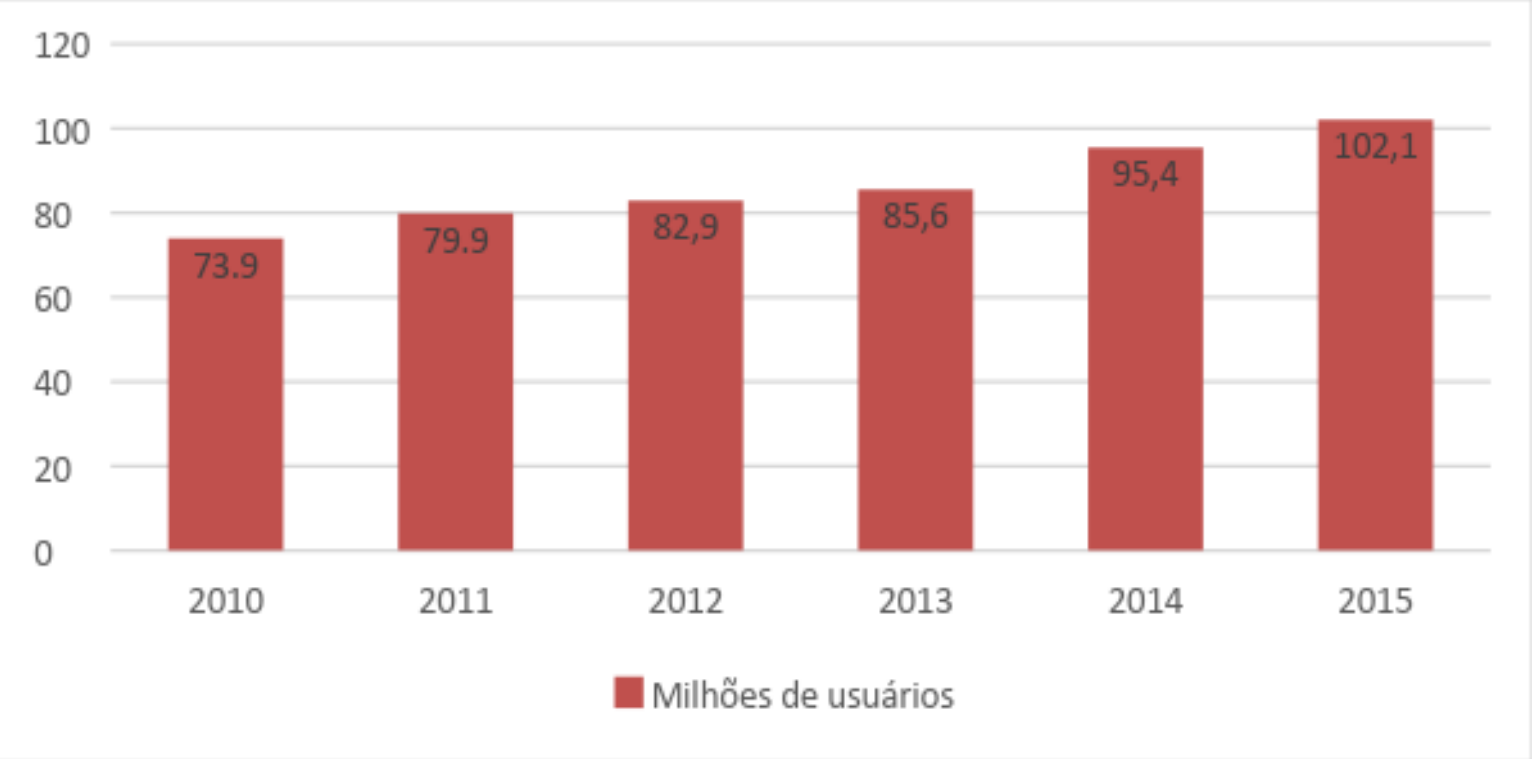

Fonte: Ibope - 2015. Adaptado pelo autor. 
O desenvolvimento da internet revolucionou também o ambiente dos negócios. De acordo com Turchi (2012, p. 13) a partir do surgimento desta rede mundial, "o ambiente digital passou a ser visto pelo setor corporativo como um terreno fértil a ser explorado e como uma maneira de atribuir maior agilidade aos negócios".

Para Zenone (2010), uma das facetas das mídias digitais são as redes sociais que aumentaram a possibilidade das empresas estarem mais próximas de seus clientes potenciais, e deste modo, terão maior possibilidade de negócios. Dentre tais está o e-commerce (Comércio Eletrônico), ou seja, uma modalidade de comércio realizado por meio de plataformas eletrônicas, tanto em computadores como por celulares. Por meio da internet, o e-commerce passa a ser um espaço ideal para se desenvolver campanhas de marketing digital e divulgar e vender seu produto e serviço.

\section{Marketing Digital}

Pode-se conceituar o Marketing Digital como ações de comunicação pelo uso da internet, telefonia celular e outros meios digitais para a divulgação de produto ou retorno de informações para a formação de um público-alvo. Tais canais têm se mostrado eficientes, devido à rapidez de veiculação e à quantidade de pessoas alcançadas (FILIPINI, 2014).

Para Gil (2013), o sucesso das empresas ao usarem o marketing digital depende de uma série de fatores como: o setor de atuação e o perfil da empresa. Além disto, é necessário desenvolver inovações gerenciais no seu uso, com o objetivo de produzir ganhos para a empresa.

Cabe então a cada empresa, analisar como pode usar o marketing digital a seu favor e o que pode fazer para trazer inovação em seu uso. Os cuidados devem ser tomados quanto à sinceridade e transparência, deste modo, a terceirização deste tipo de serviço deve ser cuidadosa para não correr o risco de reduzir a qualidade dos conteúdos produzidos. Além disso, o marketing digital de qualidade abre uma grande possibilidade de fidelizar um cliente e buscar clientes em potencial (POWELL, 2010).

Para Gil (2013), alguns aspectos são relevantes para uma empresa ao fazer uso de rede social, como a interação, a personalização de clientes e o recebimento de feedback. Assim, a empresa poderá se ater em atender os seus clientes do melhor modo possível, aumentando a sua eficácia.

Atualmente esta tecnologia está acessível a todos por meio da internet, permitindo empresas de todos os portes obter maior eficiência no contato com seu cliente, de maneira efetiva, oferecendo benefícios e satisfação das suas necessidades de modo fácil, barato e imediato.

De acordo com o Sebrae (2015), o uso do marketing digital tem conseguido alavancar as vendas de muitas pequenas empresas. Geralmente a pequena empresa não tem recursos para fazer uma ampla divulgação, mas as redes sociais têm permitido que isso aconteça. Desde restaurantes até consultoria em 
estética, o uso de ferramentas como o Facebook e Instagram tem dado grande visibilidade aos produtos e serviços a custos relativamente baixos. Além disso, por meio das redes sociais, podem-se identificar oportunidades de novos negócios.

Este recurso de visibilidade, tanto para pessoas físicas como jurídicas, oferece vantagens aos consumidores e empresários, sendo mais visíveis aos consumidores, por meio da internet, com a comodidade de ser encontrado, obtendo os dados necessários para interação, feito no conforto do seu lar, trabalho ou onde quer que esteja e em qualquer horário e dia, de maneira muito mais efetiva (FILIPINI, 2014).

É possível a criação de uma página para sua empresa e na mesma realizar a divulgação, com fotos, textos, vídeos, montagens e todo artifício que possa ser usado para chamar a atenção do maior número de pessoas possível, desta forma estando em evidência. Com a opção de "promover" a página, é possível obter mais visitantes, promover a página ou até mesmo impulsionar uma publicação específica (BERGAMASCHI, et al, 2011). De modo fácil e muito eficiente, pode-se realizar a divulgação da empresa para o público-alvo específico, pessoas interessadas, capazes de realizarem buscas e encontraram seu produto/serviço, assim aumentando a probabilidade de compra/contratação, com um baixo custo ou até mesmo sem nenhum custo (FILIPINI, 2014).

O marketing digital surgiu com a evolução da tecnologia da informação e dos meios de comunicação, em específico, a internet, através de estratégias utilizadas nas plataformas digitais. Segundo Kotler (2012), as mudanças tecnológicas, o aumento do poder cliente e a globalização são alguns aspectos que o diferem do marketing tradicional.

Conforme Kotler (2012, p. 31):

O objetivo do marketing digital é usar o poder da rede mundial de computadores interconectados juntos (Word Wide Web) para realizar um novo tipo de comunicação e de relacionamento com os consumidores, o chamado marketing interativo, no qual o relacionamento é bidirecional. Isto é, o consumidor não é passivo, mas sim ativo ao longo do processo.

Na visão de Adolpho (2013, p 13):

Os consumidores querem ter flexibilidade de escolha e escutar o que dizem sobre a marca, opiniões isentas e objetivas de pessoas comuns como ele, às pessoas querem exercer o poder de escolha que têm, para adquirir a solução que acreditam ser a melhor, e não a que a empresa lhes diga.

A divulgação da loja virtual é um item essencial para o sucesso do empreendimento, pois se trata da maneira de tornar acessível aos que desejam comprar, os produtos que a loja tem a oferecer. As mídias sociais têm se tornando uma ferramenta importante para a estratégia ou ação de marketing, pois $80 \%$ dos internautas brasileiros participam de algumas mídias ou redes sociais, fazendo com que elas 
sejam consideradas indispensáveis para as atividades empresariais como oportunidade de divulgação (TORRES, 2009).

\section{Oportunidade de Divulgação nas Redes Sociais e E-Commerce}

As redes sociais vêm crescendo cada dia mais, conquistando novos adeptos, unindo as pessoas com objetivos, gostos e pensamentos específicos, aumentando a possibilidade de interação entre as pessoas, além de possibilitar também que haja uma grande divulgação de produtos e serviços (RECUERO, 2011)

Muitas pessoas usam as redes sociais tanto para reencontrar amigos, como para interagir com novas e velhas amizades, além de conhecer novos amigos e se comunicar com pessoas que fazem parte de seu convívio social, como emprego, escola e família. A grande quantidade de pessoas que utilizam as redes sociais, a fortalecem cada vez mais, atraindo a atenção de anunciantes. Além disso, é possível por meio das redes sociais, conhecer o público alvo, sabendo quais são os seus desejos e suas necessidades. Assim, a empresa terá um melhor relacionamento com o cliente, ouvindo o que eles têm a dizer (BERGAMASCHI et al, 2011).

Outro fator, de acordo com Zenone (2010), é aproveitar a tecnologia utilizada no e-commerce, para a divulgação e retenção de clientes. Nota-se que o e-commerce (Comércio Eletrônico), é uma modalidade de comércio realizado por meio de plataformas eletrônicas, tanto em computadores como por celulares. Deste modo, a empresa terá um espaço na internet para divulgar e também para receber um parecer de seu público. Isso facilitará o relacionamento com seus clientes, possibilitando a conquista de novos clientes. O e-commerce possibilita a prospecção de grande número de pessoas.

Existem alguns aplicativos digitais de relacionamento (networking social) disponíveis na internet, como o Facebook, que podem ser entendidos como manifestações especiais e particulares de algumas redes sociais, ou como ferramentas que permitem a explicitação digital (FILIPINI, 2014).

Para Recuero (2011, p. 23):

(...) redes sociais na Internet são constituídas de representações dos atores sociais e de suas conexões. Essas representações são, geralmente, individualizadas e personalizadas. As conexões, por outro lado, são os elementos que vão criar a estrutura na qual as representações formam as redes sociais. Essas conexões, na mediação da Internet, podem ser de tipos variados, construídas pelos atores através da interação, mas mantidas pelos sistemas online. Por conta disso, essas redes são estruturas diferenciadas. Ora, é apenas por conta desta mediação específica que é possível a um ator ter, por exemplo, centenas ou, até mesmo, milhares de conexões, que são mantidas apenas com o auxílio das ferramentas técnicas. Assim, redes sociais na Internet podem ser muito maiores e mais amplas que as redes off-line, com um potencial de informação que está presente nessas conexões. 
Conforme pesquisa divulgada pela consultoria comScore (2015), os brasileiros estão no topo da lista quando se trata de tempo em redes sociais, obtendo uma média de 650 horas por mês, e média de utilização $60 \%$ maior que o resto do planeta.

De acordo com Tomaél et al (2015, p. 14):

\begin{abstract}
A rede, que é uma estrutura não-linear, descentralizada, flexível, dinâmica, sem limites definidos e auto organizável, estabelece-se por relações horizontais de cooperação. Com base em seu dinamismo, as redes, dentro do ambiente organizacional, funcionam como espaços para o compartilhamento de informação e do conhecimento. Espaços que podem ser tanto presenciais quanto virtuais, em que pessoas com os mesmos objetivos trocam experiências, criando bases e gerando informações relevantes para o setor em que atuam.
\end{abstract}

A penetração das redes sociais em pequenas e médias empresas nos Estados Unidos já é uma realidade, sendo utilizada por $31 \%$ destas empresas. Estudos apontam que se $70 \%$ das pequenas empresas norte americanas implementaram o uso de redes sociais em sua divulgação, agregaram um valor de 900 bilhões de dólares ao ano (GIL, 2013).

Para as organizações, além de divulgação, é possível, por meio das redes sociais, captar informações importantes do público-alvo, como: comportamento, preferências alimentares, laser, necessidades e outros fatores que podem ser explorados pela empresa, com o objetivo de oferecer o seu produto ou serviç̧o (GIL, 2013).

Pode-se definir então as redes sociais como um conjunto de pessoas, com algum padrão de contatos ou interações, onde se estabelecem diversos tipos de relações e, por meio delas, circulam fluxos de informação. Entende-se também, que estas interações e trocas de informações são no âmbito global e, portanto, que podemos estar conectados e informados sobre tudo que ocorre no mundo todo em tempo real (BERGAMASCHI, et al, 2011).

Existem diversas pessoas conhecidas nas redes sociais que são formadoras de opiniões neste meio, as quais os demais usuários acreditam piamente nos depoimentos de satisfação (ou não) com produtos e serviços adquiridos ou usados. A possibilidade de aumentar os relacionamentos, por meio da internet, é algo que tem fascinado as pessoas, e tornado cada vez maior o número de adeptos. Nas redes sociais, cada usuário se torna um ator, podendo expressar as suas individualidades, gostos e se agrupar a pessoas que possuam os mesmos interesses (RECUERO, 2011).

Assim, tais mídias se tornam excelentes lugares para que as empresas explorem e apresentem os seus produtos, além de poder entender quais são as preferências de seu público-alvo. Deste modo, além de divulgação, pode-se usar as redes sociais como instrumento de pesquisa, algo interessante para melhorar e/ou direcionar a divulgação (GIL, 2013).

Para Adolpho (2013), mensurar resultados em redes sociais não é uma tarefa fácil, pois muitos 
confundem este tipo de divulgação com outras que existem na internet como sites, blogs, e-mail marketing e outros. A diferença, no caso das redes sociais, é o capital social e não financeiro que conta. Ou seja, a empresa precisa ter uma grande quantidade de "amigos" em sua rede, para melhor divulgar o seu trabalho.

Para Jenkins (2013), o maior fascínio das redes sociais está justamente na interação que há entre pessoas e celebridades ou empresas. Se todas as mídias fizessem uma convergência para as redes sociais, seria mais simples saber a opinião do público de modo instantâneo.

As empresas precisam, então, estarem atentas e todas as oportunidades para divulgar e fortalecer o seu negócio e atualmente, nada evoluiu tanto como o acesso das pessoas à internet e às redes sociais. A internet conseguiu alcançar em cinco anos um número de usuários que o sistema de telefonia levou 35 anos para conseguir. Sem dúvida este é um fenômeno de divulgação (FILIPINI, 2014).

Para Gil (2013), muitas empresas deixam de obter maiores receitas, perdendo muito dinheiro todo ano, por não saberem utilizar adequadamente as redes sociais como ferramenta de divulgação e feedback.

Assim, para que uma empresa possa aproveitar este espaço para divulgar seu produto ou serviço, deve ter atitudes como persistência, habilidade de busca e manter a capacidade do usuário de replicar o conteúdo quantas vezes for necessário (RECUERO, 2011).

\section{Estágio da Decisão da Compra do Consumidor}

Um dos grandes desafios para as empresas é compreender o comportamento do consumidor e em que momento este tomará a decisão pela compra de um produto ou serviço. Assim, para a teoria de marketing, se faz relevante que haja um estudo de tal comportamento, onde se analisa os processos envolvidos, o uso e descarte de produtos e as necessidades e desejos do consumidor (KOTLER; KELLER, 2006).

De acordo com Karsaklian (2011, p. 13), "ser consumidor é ser humano. Ser consumidor é alimentar-se, vestir-se, divertir-se, é viver”. Assim, para que haja um consumo, o indivíduo precisa definir as suas necessidades e a partir daí, buscar os itens que precisa e que estão disponíveis.

Abraham Maslow, um importante psicólogo americano, da década de 1950, mencionou que o homem se motiva quando suas necessidades são satisfeitas de forma gradual, respeitando certa hierarquia. Com a utilização de uma pirâmide, Maslow colocava os desejos de consumo divididos por estágio, onde na base da pirâmide estavam os mais prementes e no topo os menos importantes. Segundo sua teoria, o homem só passaria para o estágio seguinte da pirâmide, depois que satisfizesse a necessidade mais premente, e assim iria subindo degrau a degrau, como se houvesse uma hierarquia. A 
pessoa assim seria promovida a um estágio mais alto da pirâmide, conforme fosse satisfazendo suas necessidades (CARAVANTES, 2004).

Maslow não estava interessado em analisar o comportamento de consumo e nem avaliar os estágios para a decisão de compra, mas buscava desenvolver uma ideia sobre a motivação de cada ser humano. Assim, de acordo com o seu estudo, o indivíduo cria 5 planos básicos de necessidade em sua vida. São esses: satisfazer necessidades fisiológicas, de segurança, de afeto, de relacionamento e de auto realização (GIGLIO, 2005).

Figura 1. Pirâmide de Maslow Fonte: Caravantes (2004).

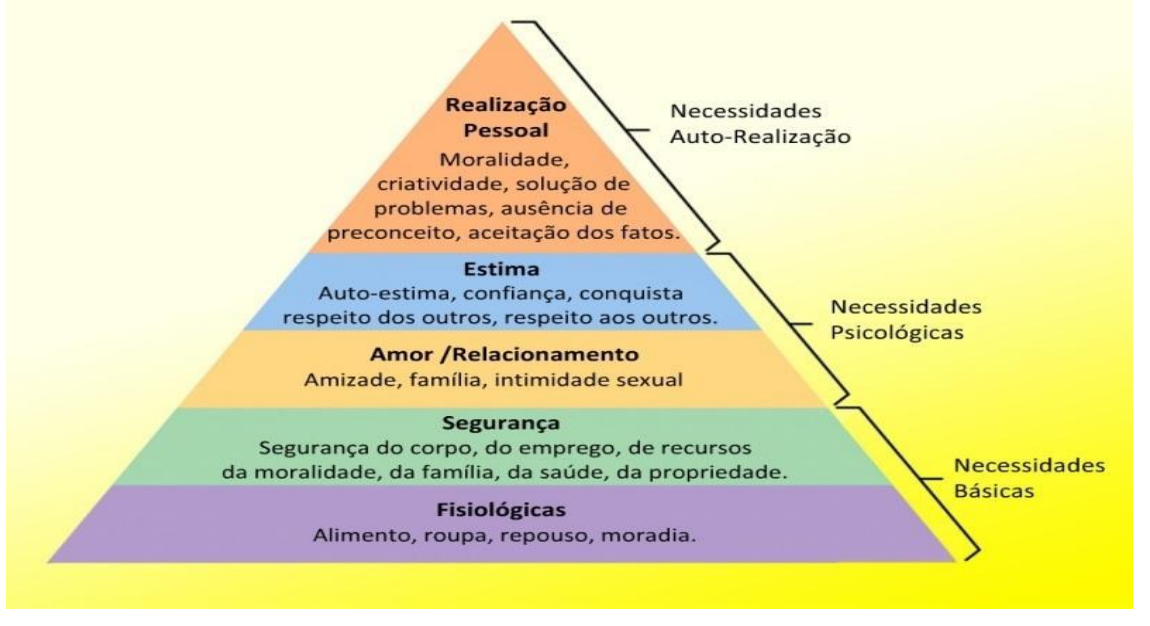

As necessidades fisiológicas são as necessidades básicas de sobrevivência como fome, sede e sono; a necessidade de segurança física é obter um teto e roupas; afeto tem a ver com a necessidade de ser aceito pelas pessoas, incluindo atividades sexuais e o comportamento de viver em um grupo como família ou círculo de amizade.

Em muitos casos, depois de satisfazer tais necessidades, a pessoa busca a auto realização, ou seja, a necessidade de ser encarado pelos outros como alguém inteligente, forte ou detentor de outras qualidades relacionadas à necessidade de status. Assim, a empresa precisa entender quais são as reais necessidades de seus colaboradores e buscar supri-las na medida do possível. (CARAVANTES, 2004).

De acordo com Kotler e Keller (2006), uma vez que o objetivo do marketing é atender as necessidades e os desejos do consumidor, se torna fundamental que se conheça o comportamento de compra. Assim, o estágio de decisão de compra do consumidor contempla as seguintes etapas: reconhecimento da necessidade, busca de informações, procura por solução, avaliação das opções, decisão da compra e por fim, a análise de satisfação da compra. Além disso, é interessante notar as influências psicológicas que atuam na decisão pela compra, sendo estas: motivação, percepção, 
aprendizagem, crenças e atitude.

\section{Metodologia}

A metodologia do presente artigo foi embasada em uma pesquisa quantitativa, descritiva, onde se utilizou técnicas estatísticas para quantificar em números as opiniões dos pesquisados. A pesquisa descritiva tem como finalidade descrever as características do público ou população pesquisada Yin (2010). Quanto a pesquisa quantitativa, este tipo de pesquisa tem como escopo compreender e enfatizar o raciocínio lógico trazendo informações que contribuirão para que se possa mensurar as experiências humanas (MIGUEL, 2010).

Interessante notar que, uma vez que foi aplicada uma pesquisa quantitativa, para a os habitantes da região do Cariri com idade entre 18 a 70 anos, por se tratar de um público com vida social ativa, usuários e não usuários de serviços de banda larga, nota-se que o uso de pesquisa descritiva se torna relevante, esclarecendo as características desta população, sendo possível alcançar uma amostra de 244 pessoas.

A presente pesquisa quantitativa e descritiva teve como objetivo analisar o impacto que as campanhas de marketing digital via redes sociais e e-commerce, praticadas pelas empresas de banda larga na região do Cariri, podem causar na decisão de compra dos consumidores. Neste contexto, de acordo com Yin (2010), é preciso que se considere em uma pesquisa quantitativa, que embora se deva conseguir o maior número possível de uma amostra, não existe um ponto definido de término, onde se possa comprovar de forma confirmatória as evidências do estudo. Assim, nota-se que neste caso, a ocorrência de margem de erro.

A forma de abordagem consistiu em um questionário estruturado, colocado na plataforma Google (www.google.com.br), cuja ordem e redação permanecem invariáveis para todos os pesquisados. Desta forma tornou-se possível o tratamento quantitativo dos dados e o desenvolvimento.

O procedimento técnico foi realizado por meio de levantamento de informações utilizando um processo de interrogação, onde se pôde obter informações sobre o comportamento dos pesquisados.

Como instrumento de coleta de dados optou-se por utilizar um questionário online, enviado através de link e publicações via Whatsapp, Facebook, Instagram e E-mail, utilizando o Google Forms. O questionário é autoaplicável, de múltipla escolha, sobre conceitos relacionados ao marketing digital das empresas de banda larga na região. Foi considerado um tempo estimado de resposta de 3 minutos.

Quanto a análise de dados, essa se deu por meio de uma análise estatística, com a utilização de planilhas e gráficos. Foi realizada uma análise estatística básica do questionário respondido por meio de 
questões fechadas para avaliar como está a qualidade dos serviços supracitados. A análise dos dados coletados foi realizada através do software Excelß, com tabulação em planilhas e análises gráficas.

\section{Análise e Discussão dos Resultados}

Inicialmente foi perguntado aos respondentes, quantos utilizam o serviço de banda larga na região do cariri. O resultado está apresentado no Gráfico 2 abaixo:

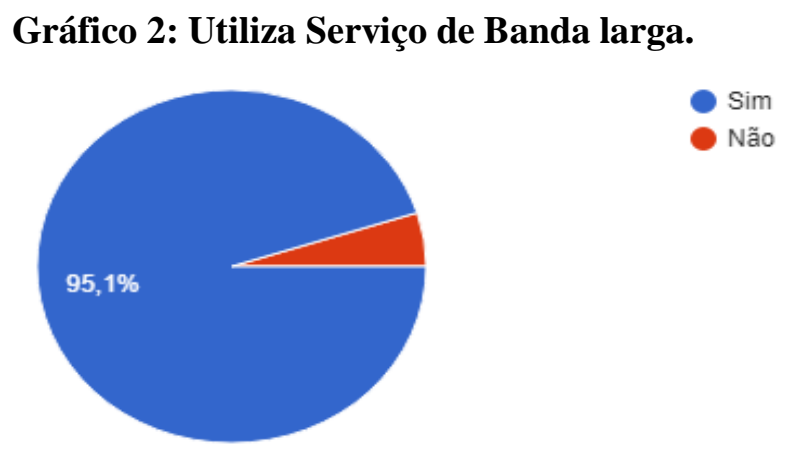

Fonte: Pesquisa Direta (2018).

De acordo com o resultado da pesquisa, nota-se que $95,1 \%$ dos entrevistados utilizam o serviço de banda larga. Assim, o universo dos entrevistados pode acarretar informações relevantes para a presente pesquisa, pois a grande maioria do público está inserido nas questões levantadas pelo presente trabalho.

Esse dado revela que a maioria das pessoas possuem acesso a internet por meio de banda larga, uma vez que se trata de uma tendência tecnológica. Esse fator está de acordo com Turchi (2012), onde menciona que o crescimento deste ambiente digital, também chamado de grande teia mundial, ocorreu de forma acelerada e mantém-se em contínua evolução, tanto em número de usuários, como também em possibilidades que se refere à obtenção e oferta de entretenimento, cultura e informação, ampliação de relacionamentos e, principalmente, para realização de negócios. Albertini (2010), corrobora com tal informação, por mencionar que a infraestrutura da internet, em banda larga, possui capacidade para atingir, além de aplicações tecnológicas da informação, outros setores ligados a compras, prestação de serviço e mensagens como e-mail e outros.

Em seguida, procurou-se saber a idade dos pesquisados, notou-se o seguinte perfil de acordo com o Gráfico 3. 


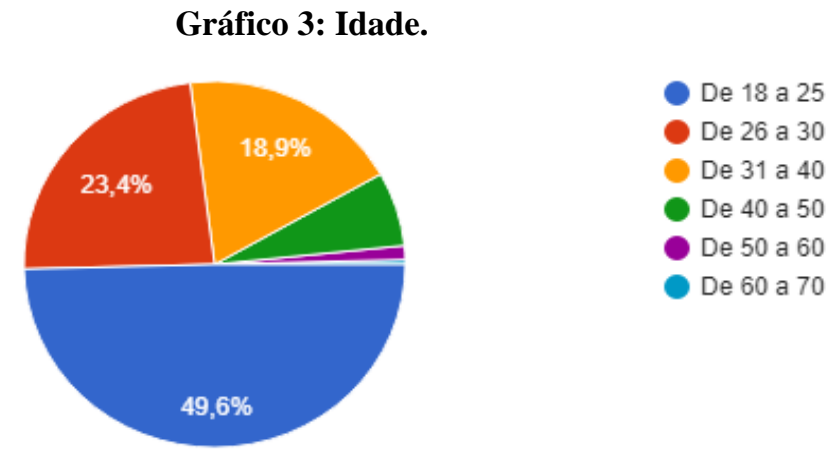

Fonte: Pesquisa Direta (2018).

Percebe-se que, quase metade dos entrevistados possuem entre 18 e 25 anos. 23,4\% têm entre 26 e 30 e 18,9\% entre 31 e 40 anos. Nota-se então que o público com maior inclinação de uso de internet banda larga na região do cariri, está entre 18 e 30 anos. Assim, percebe-se ser um público mais jovem, em comparação com os outros entrevistados, deste modo as empresas podem aproveitar-se desta faixa etária, para intensificar o relacionamento por meio de marketing digital.

Esse indicativo mostra que o marketing via redes sociais tende a ser uma grande força, uma vez que as pessoas das idades apontadas no gráfico acima estão cada vez mais conectadas por meio de redes sociais. Podendo desta forma, as empresas do segmento de telefonia, trabalharem campanhas específicas voltadas para esse público com tal faixa de idade, publicando conteúdo, seguindo sempre as últimas tendências da atualidade, com imagens e uma linguagem jovem.

De acordo com Gil (2013), alguns aspectos são relevantes para uma empresa ao fazer uso de rede social, como a interação, a personalização de clientes e o recebimento de feedback. Assim, a empresa poderá se ater em atender os seus clientes do melhor modo possível, aumentando a sua eficácia. Em adição a isso, Zenone (2010) menciona que ser essencial que as empresas tracem estratégias definidas quanto ao modo como realizará o seu atendimento em nível global.

Logo após buscou saber o meio de acesso à internet dos respondentes. Tem-se a seguinte informação:

Gráfico 4: Meio de acesso.

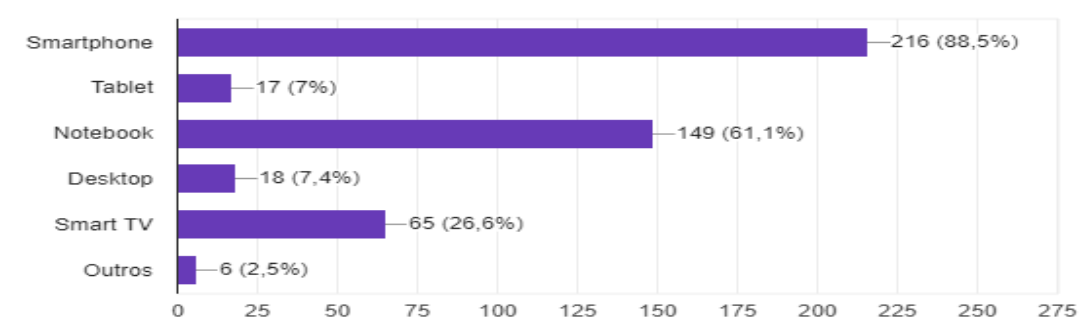

Fonte: Pesquisa Direta (2018). 
Pode-se observar que o meio de acesso mais comum para acesso da internet é por meio de smartphone, sendo 216 dos 244 pesquisados O uso de Notebook fica em segundo lugar, $61 \%$ dos pesquisados correspondendo a 149 deles. Assim, entende-se que criar mídias específicas para o uso em smartphones é também uma saída interessante de relacionamento. Deste modo, as empresas devem buscar desenvolver também aplicativos específicos para smartphones, desenvolverem a comunicação via WhatsApp, e outras redes sociais, sempre respondendo a perguntas críticas, sugestões e elogio em tempo real, pois esse é o perfil do público alvo neste caso.

Tal fator é relevante, pois de acordo com o IBGE (2018), 77,1\% dos brasileiros possuem algum celular, sendo grande número de smartphones com acesso à internet. Isso é consoante com os dizeres de Zenone (2010), que menciona quem uma das facetas das mídias digitais são as redes sociais que aumentaram a possibilidade das empresas estarem mais próximas de seus clientes potenciais, e deste modo, terão maior possibilidades de negócios.

Quanto ao modo de como os usuários vieram a adquirir o serviço de banda larga. Obteve-se o seguinte resultado:

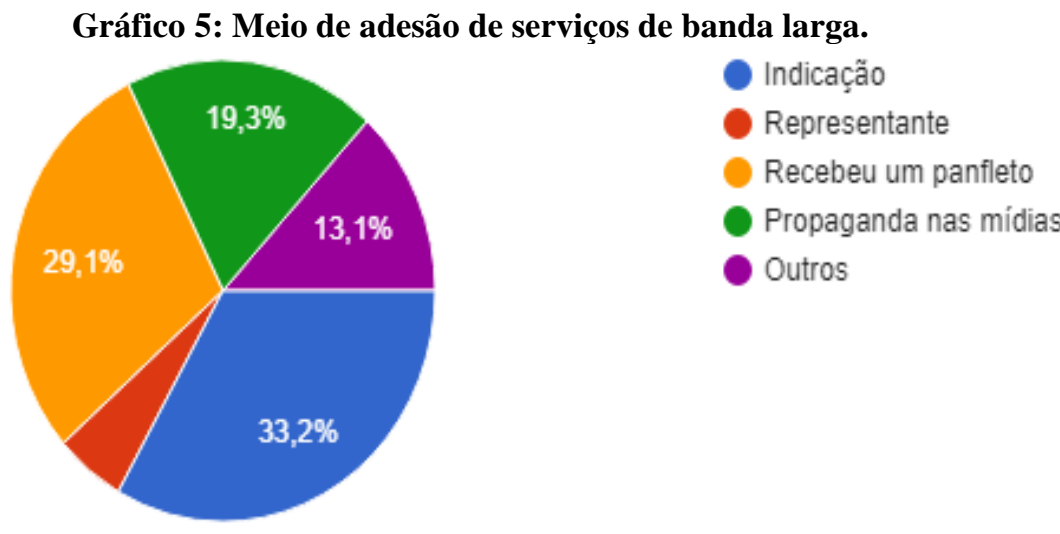

Fonte: Pesquisa Direta (2018).

Nota-se que 33,2\% foi por meio de indicação, 29;1\% por meio de panfletagem, 19,3\% por meio de propostas de mídia. Percebeu-se que existem dois meios eficazes de conquista de clientes nessa área, por meio de indicação e por meio de panfletagem. Esse fator revela que a prestação de um bom serviço tende a ser o meio mais eficaz de se conquistar mais clientes, pois possibilita maiores indicações.

$\mathrm{O}$ uso de representantes se mostrou o meio de menor resultado, representando apenas 5,3\% dos clientes conquistados. Nota-se também que as propostas de mídia representam 19,3\%, porém, com maior intensidade de mídias sociais, pode ser que haja um aumento também na captação de clientes, por esse meio. 
Haja vista, que de acordo com a pesquisa as empresas ainda mantém os tradicionais meios de ações e divulgações, como a indicação que é o famoso método "boca a boca" e a panfletagem. Isso mostra que as empresas que têm investimento em redes sociais mais ainda não é o suficiente para atingir seu público com suas campanhas. Sugere campanha estrategicamente direcionadas a cada público e faixa de idade correta, atendimento personalizado e em tempo real nas redes sociais, já fechando a venda com o cliente aderindo o serviço.

De acordo com Powell (2010), cabe então a cada empresa, analisar que tipo de marketing vai utilizar a seu favor e o que pode fazer para trazer inovação em seu uso. Os cuidados devem ser tomados quanto à sinceridade e transparência, deste modo, a terceirização deste tipo de serviço deve ser cuidadosa para não correr o risco de reduzir a qualidade dos conteúdos produzidos.

Quanto ao nível de satisfação com o atendimento apresentada pelas prestadoras em plataformas digitais.

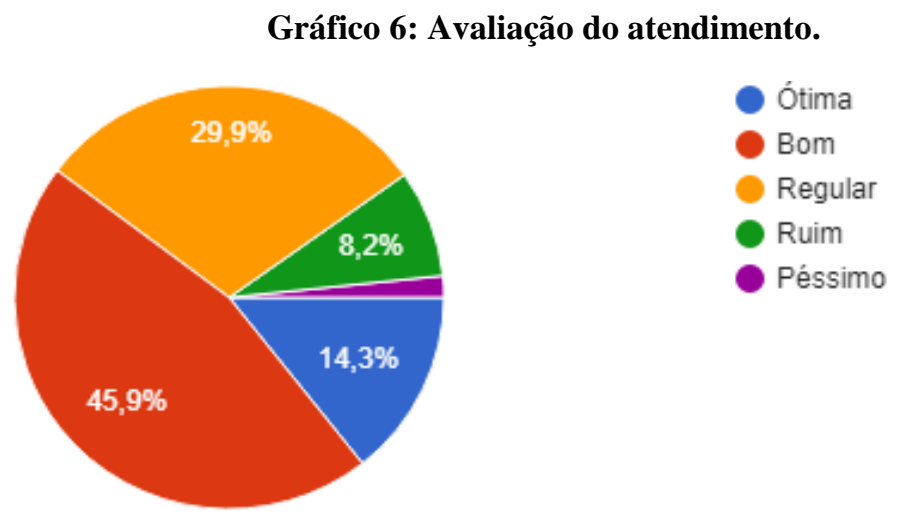

Fonte: Pesquisa Direta (2018).

Nota-se que quase metade dos entrevistados avaliaram como bom o atendimento das operadoras por meios digitais, correspondendo a 45,9\%. Com avaliação regular obteve-se $29,9 \%$. Ruim foi de apenas $8,2 \%$. A avaliação como ótimo foi de $14,3 \%$. Assim, se for somada a avaliação como bom é ótima, temos $60,2 \%$ dos entrevistados. Isso demonstra o potencial que as operadoras possuem em atenderem por meios digitais e com qualidade.

Visto no gráfico que $45,9 \%$ avaliaram como bom o atendimento por meios digitais, isso mostra satisfação por partes dos consumidores, mais ainda tem muito a melhorar, pois como mostra a pesquisa apenas $14,3 \%$ avaliaram como ótimo, sendo esse número poderia ser bem maior satisfatoriamente se por parte das empresas tivesse um melhor atendimento através dessas plataformas, (se possível acrescentar mais algo e citando sobre os atendimentos).

Não se deve desperceber também que, de acordo com Recuero (2011), existem diversas pessoas conhecidas nas redes sociais que são formadoras de opiniões neste meio, as quais os demais usuários 
acreditam piamente nos depoimentos de satisfação (ou não) com produtos e serviços adquiridos ou usados. Assim, agradar o maior número de pessoas, pode trazer resultados satisfatórios.

O modo como a empresa realiza o contato com o cliente foi a próxima pergunta dirigida aos pesquisados. O resultado foi o seguinte de acordo com o Gráfico 7.

\section{Gráfico 7: Contato entre empresa e cliente.}

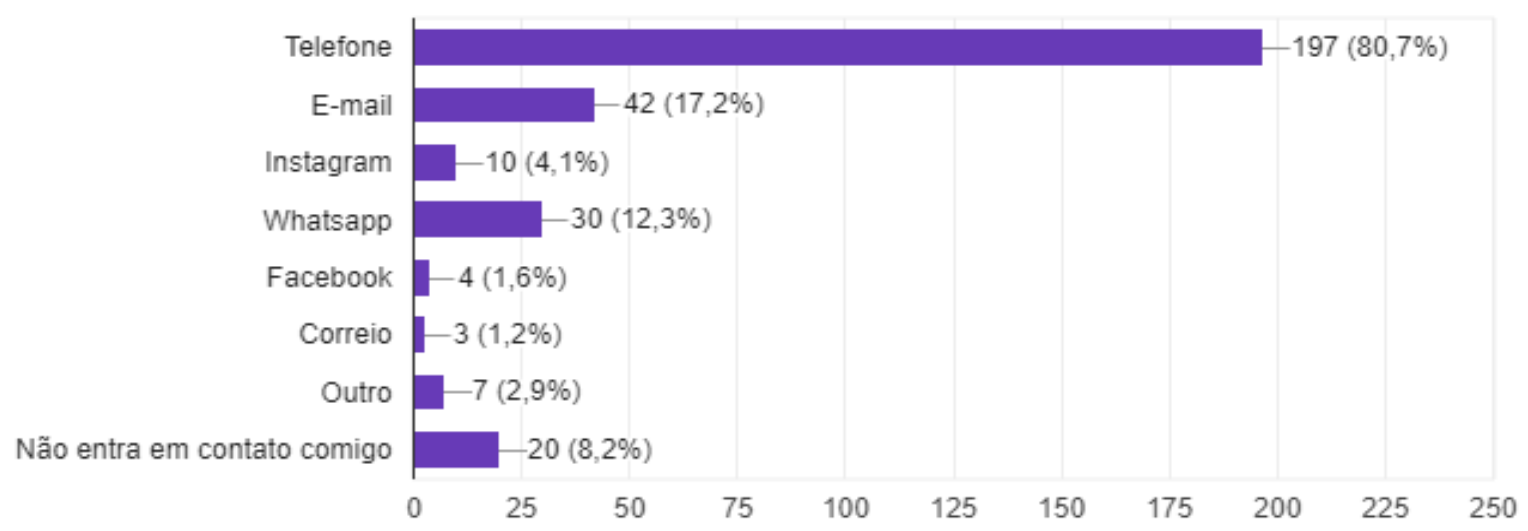

Fonte: Pesquisa Direta (2018).

Nota-se que o uso de contato telefônico é o meio mais utilizado correspondendo a 80,7\% dos contatos. Assim percebe-se que ainda há campo para melhorar no contato com cliente por meio de mídias digitais, onde poderia ser utilizado SMS, WhatsApp e dentre outros meios disponíveis com menor custo e com alcance de atendimento simultâneo bem maior.

Neste contexto, pode-se mencionar os dizeres de Bergamaschi et al, (2011), onde menciona que a empresa terá um melhor relacionamento com o cliente, ouvindo o que eles têm a dizer. Assim, o fluxo de informações por meio de SMS, WhatsApp e outros é fundamental. Outro fator a considerar, de acordo com Zenone (2010), é aproveitar a tecnologia utilizada no e-commerce, para a divulgação, retenção de clientes e recepção de feedback.

Desta vez procurou-se saber qual o meio divulgação de produtos e serviços pelas operadoras de banda larga do Cariri, obteve-se o seguinte resultado, de acordo com o Gráfico 8: 


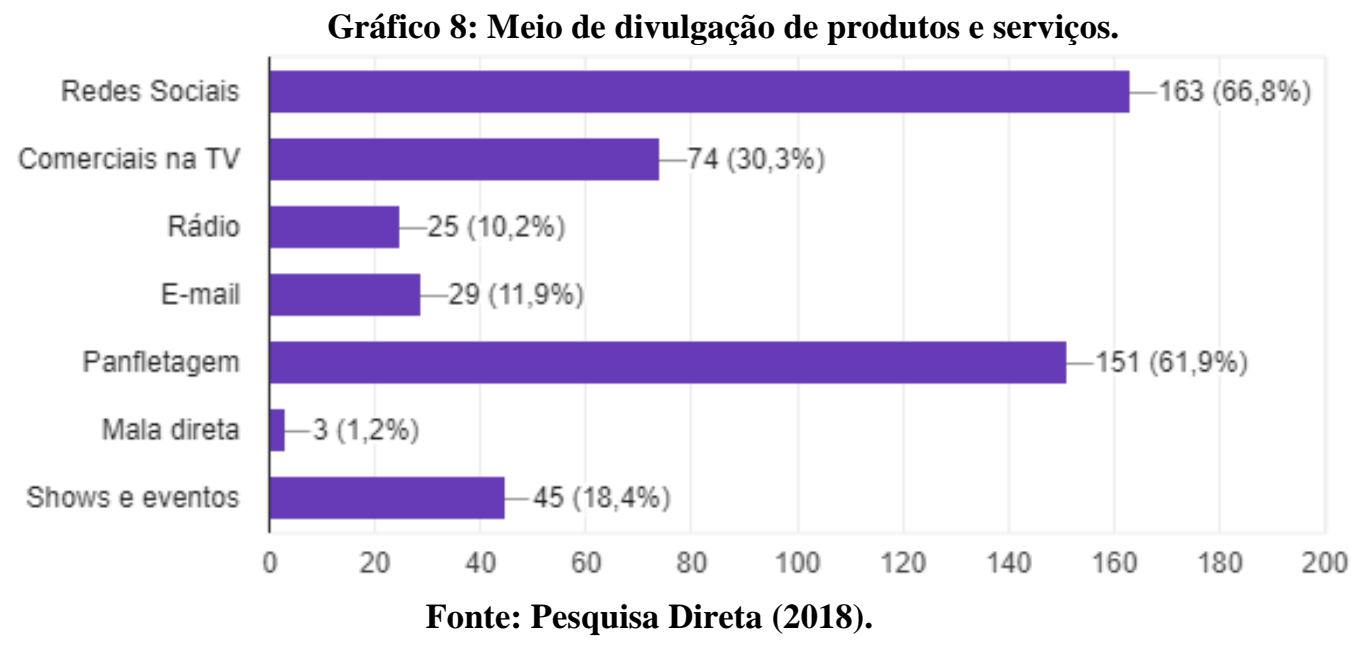

No aspecto da divulgação, pode-se perceber que as empresas estão fazendo um bom uso das redes sociais, pois dos entrevistados, $66,8 \%$ recebem por esse meio. Nota-se também que o uso de panfletos ainda tem sido muito recorrente, chegando a 61,9\% dos entrevistados. Comerciais de TV são também utilizados, sendo esta a resposta de 3,3\% dos pesquisados. Como a questão deu ao entrevistado a oportunidade de escolher uma ou mais opções, a soma de resultados neste caso ultrapassa os $100 \%$.

Percebe-se que as empresas estão entendendo o impacto que as redes sociais têm em fazer a divulgação, bem como em manter o relacionamento com o cliente. Isso é interessante, pois os comerciais de TV que eram muito requisitados, ficaram para segundo plano, de acordo com o gráfico acima. Porém a panfletagem ainda é muito utilizada.

Isso está de acordo com o que menciona Albertini (2010), descrevendo que ocorreriam algumas transformações na sociedade onde a internet e as redes sociais alcançaria um crescimento enorme e se tornaram uma grande e valiosa oportunidade de negócio. Além disso, o e-commerce passou a ser um valioso meio de vendas. Esse fator aponta para a importância desta nova comunicação, que juntamente com o surgimento da economia digital o mundo passou a processar as informações de uma forma mais rápida, eficaz e com custo reduzido.

Em seguida buscou identificar se os usuários pesquisam nas redes sociais, sites de reclamação e nos sites das empresas informações sobre reputação, serviços oferecidos e assim por diante. Obtevese o seguinte resultado: 


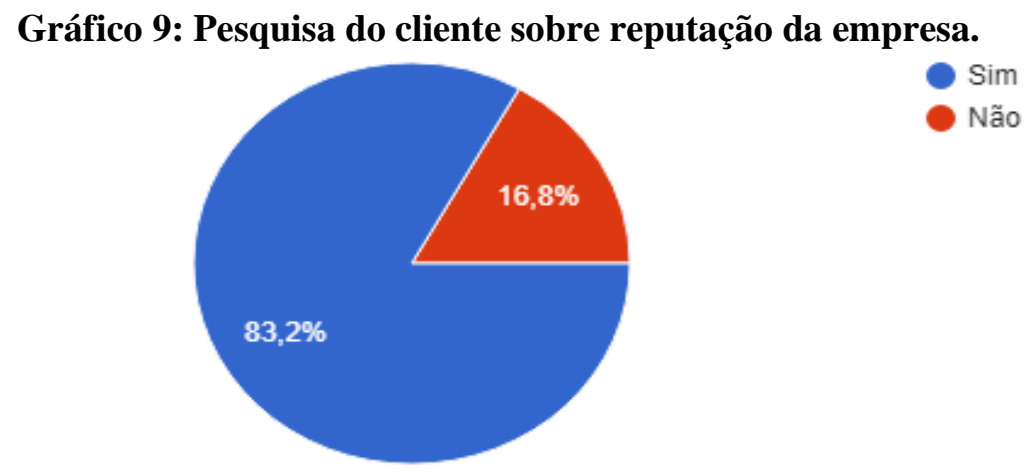

Fonte: Pesquisa Direta (2018).

Pode-se perceber por meio do Gráfico 9 que 83,2\% dos usuários costumam pesquisar em redes sociais e em sites das empresas, a sua reputação e a qualidade dos serviços oferecidos por ocasião do interesse da contratação. Assim, as empresas precisam estar atentas e essa tendência e procurar estabelecer uma boa relação com o cliente, por meio das mídias sociais, dando sempre atenção e o bom atendimento, não somente nas redes sociais, mais também em lojas físicas, no atendimento telefônico, atendimento porta a porta, suporte técnico e qualidade nos serviços oferecidos. Qualquer falha por parte das empresas em qualquer um desses canais citados acima pode afetar na reputação das empresas nos fóruns online, sites de reclamações e nas redes sociais.

Para Kotler (2012), as empresas precisam se atualizarem, para realizar um novo tipo de comunicação e de relacionamento com os consumidores, o chamado marketing interativo. Isso trará aos consumidores informações valiosas sobre a empresa, impactando na conquista de novos clientes.

Neste contexto, buscou-se analisar o tipo de informação que os usuários pesquisam. O resultado está descrito no Gráfico 10:

Gráfico 10: Informações buscadas pelos clientes.

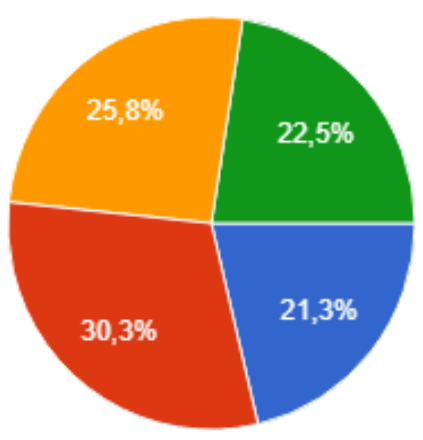

Promoções

Preços Baixos

Reputação

Benefícios Ofertados

Fonte: Pesquisa Direta (2018). 
Por ordem de assunto, as informações mais procuradas pelos usuários são: preços baixos 30,3\%, reputação $25,8 \%$, benefícios ofertados $22,5 \%$ e promoções $21,3 \%$. Assim, além de um bom relacionamento com o cliente, as empresas devem buscar ofertar serviços com bom preço, mantendo também uma reputação de qualidade.

Para Zenone (2010) o ambiente virtual é um espaço interessante para divulgar e também para receber um parecer de seu público, facilitando o relacionamento com seus clientes, possibilitando a conquista de novos clientes. Deste modo, é importante que a empresa mantenha o seu ambiente virtual, que seja um site, aplicativo ou rede social, de modo chamativo e de fácil compreensão. Neste sentido, Adolpho (2013), salienta que os consumidores querem ter flexibilidade de escolha e escutar o que dizem sobre a marca, opiniões isentas e objetivas de pessoas comuns como ele, às pessoas querem exercer o poder de escolha que têm, para adquirir a solução que acreditam ser a melhor, e não a que a empresa lhes diga.

Com respeito a notificações em datas especiais, obteve-se o seguinte resultado.

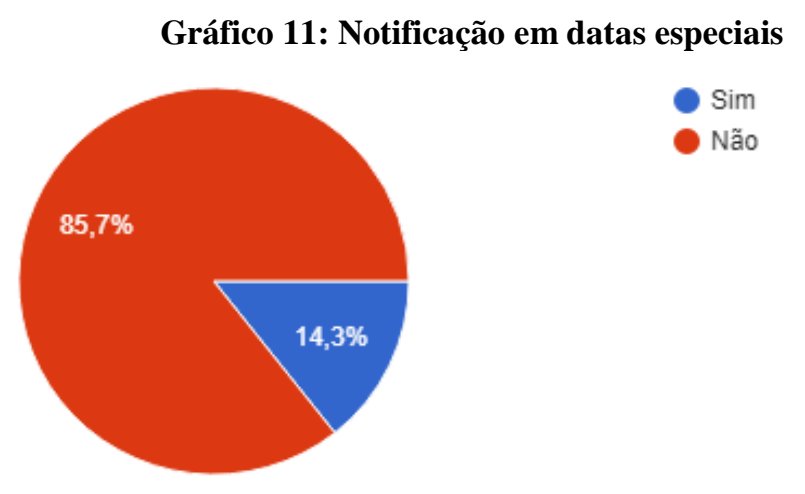

Fonte: Pesquisa Direta (2018).

Nota-se, por meio do Gráfico 11 que há um grande campo de melhora por parte das operadoras em explorar datas especiais como aniversários, para entrar em contato com os clientes, mantendo o bom relacionamento, atenção e abrindo oportunidades de vendas dos demais serviços que a empresa oferece, uma vez que $85,7 \%$ dos entrevistados não são contatados em tais eventos.

Kotler (2012), menciona que a empresa deve criar um relacionamento bidirecional, onde ela entra em contato com os clientes e pode também receber informações. Datas e eventos especiais, são ocasiões propícias para isso. Para Filipini (2014), as pessoas gostam de se sentir especiais e importantes para a empresa. Assim, tratá-la de modo personalizado será algo de muito valor para o relacionamento com o cliente. 
Em seguida procurou-se entender o meio de comunicação que os pesquisados usam para apresentar suas reclamações as operadoras. O Gráfico 12 apresenta o seguinte resultado:

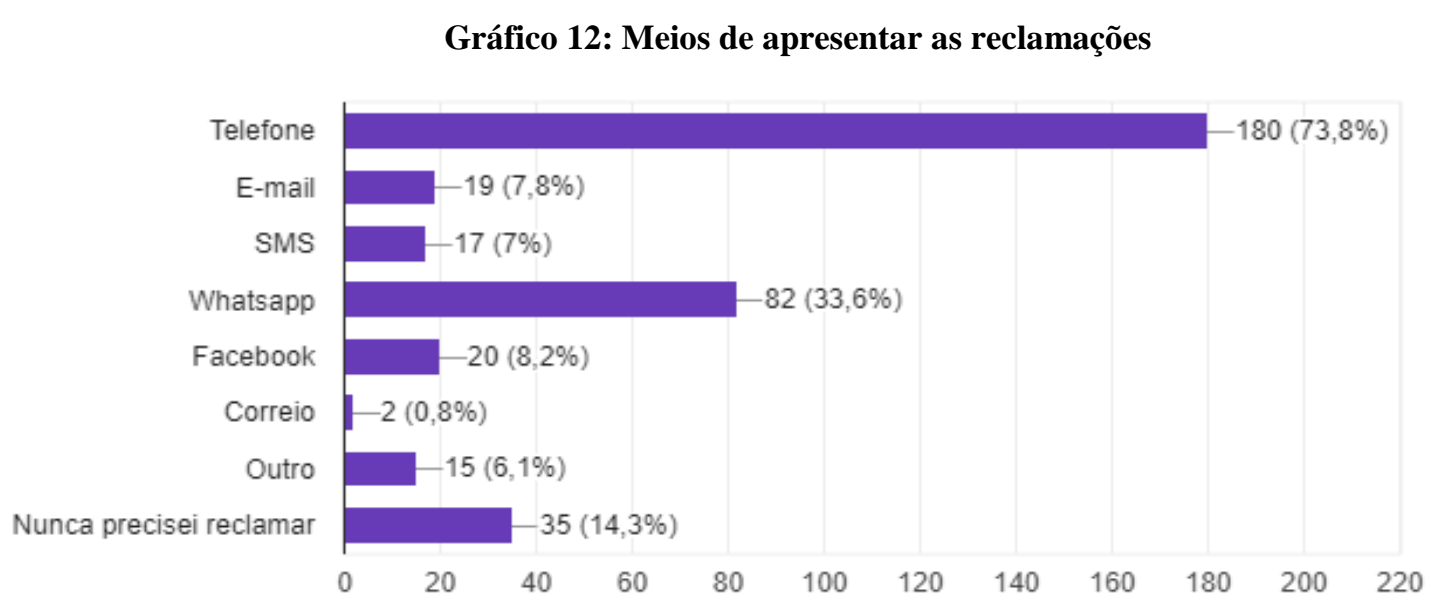

Fonte: Pesquisa Direta (2018).

Nota-se que dentre os entrevistados, a maioria utilizou o telefone para fazer contato, seguido por e-mail, WhatsApp e outros. Apenas $14,3 \%$ dos entrevistados nunca precisaram reclamar. Esse dado é relevante, pois nota-se que há uma carência de bons serviços prestados na região do Cariri, onde as operadoras que buscarem soluções poderão obter vantagem competitiva.

Visto que o telefone ainda é o meio mais utilizados pelos entrevistados para entrar em contato com operadoras de seus serviços de banda larga tendo assim 73,8\% dos entrevistados, seguido por WhatsApp com 33,6\% apontado pelos entrevistados, cabe às empresas de banda larga da região do cariri aumentar seus canais de atendimento ao cliente, criar plataformas como aplicativos onde o cliente possa realizar seu auto atendimento de simples solicitações.

Um exemplo neste sentido é apontado por Filipini (2014), mencionando que existem alguns aplicativos digitais de relacionamento disponíveis na internet, como o Facebook, que podem ser entendidos como manifestações especiais e particulares de algumas redes sociais, ou como ferramentas que permitem a explicitação digital. Assim, o desenvolvimento de aplicativos para que o cliente possa se manifestar seria um meio interessante de beneficiar o consumidor e mostrar consideração por suas opiniões ou reclamações.

No que se refere a classificação do uso das redes sociais pelas operadoras, obteve-se os seguintes resultados, conforme Gráfico 13: 
Gráfico 13: Uso das redes sociais pelas empresas.

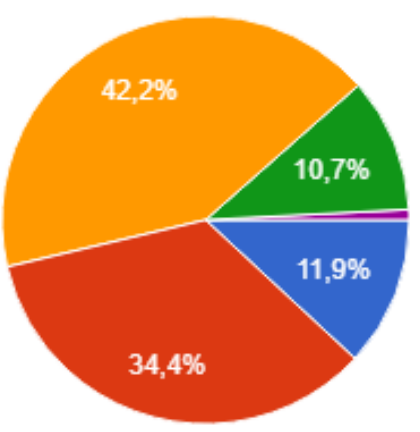

Ótimo

Bom

Regular

Ruim

Péssimo

Fonte: Pesquisa Direta (2018).

Nota-se que, segundo a maioria dos usuários, o desempenho do uso de redes sociais pelas operadoras é regular e médio. Assim, ainda há um grande campo de trabalho em tais mídias digitais, onde se poderia aproveitar a quantidade de pessoas conectadas para realizarem a divulgação de seus serviços.

Tal fator deve ser considerado por todas as empresas, independentemente de seu por, mas, de acordo com o Sebrae (2015), isso é mais importante para a pequena e micro empresa, pois geralmente a pequena e micro empresa não tem recursos para fazer uma ampla divulgação, assim sendo, as redes sociais têm permitido que isso aconteça a custos relativamente baixos.

Quanto ao sentimento de fidelização dos pesquisados em relação as operadoras, o Gráfico 14 apresenta o seguinte resultado:

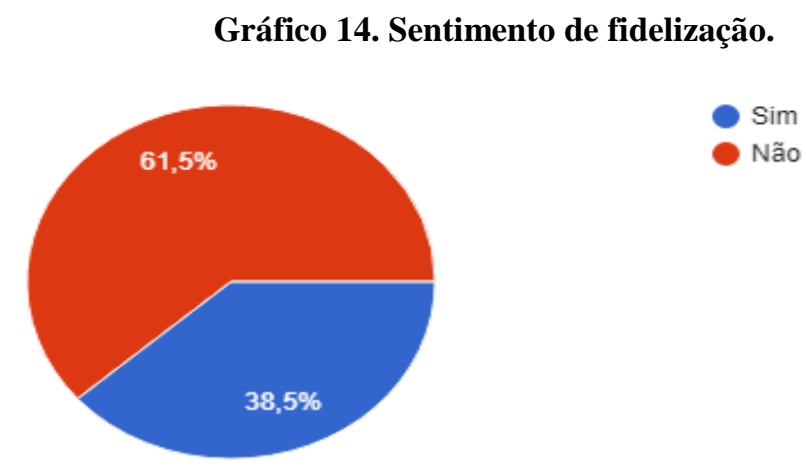

Fonte: Pesquisa Direta (2018).

Nota-se que a maior parte dos entrevistados não se sentem fidelizados pelas empresas de banda larga que utilizam. Assim, as empresas precisam buscar meios, quer seja por sites, aplicativos ou mesmo por meio das redes sociais mais utilizadas, modos de criar uma melhor fidelização, pois há muita 
concorrência neste segmento e a fidelização pode fazer uma grande diferença para a sua competitividade. Para Filipini (2014), o Facebook, Instagram e WhatsApp, são meios eficientes e baratos de se conseguir fidelizar um cliente e manter com este um importante relacionamento.

Quanto ao acesso do site da provedora de internet por parte dos respondentes, o Gráfico 15 apresenta o seguinte resultado:

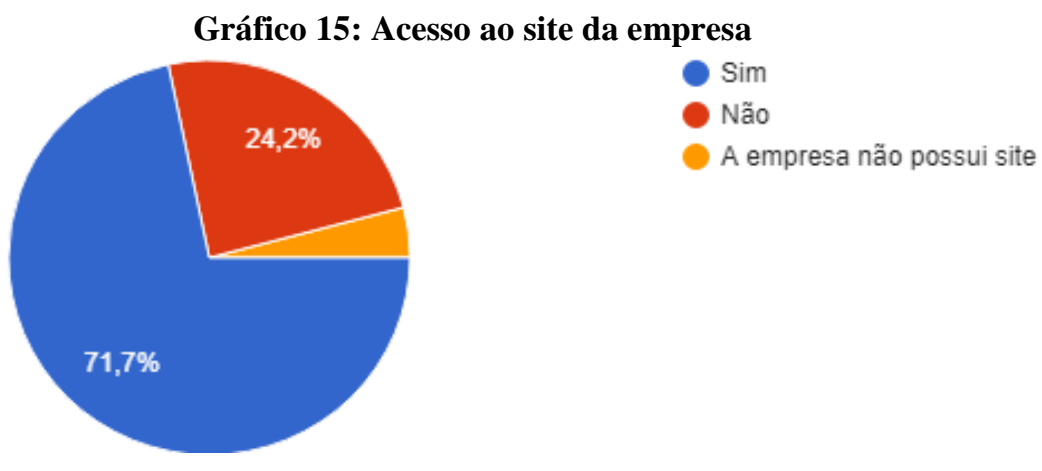

Fonte: Pesquisa Direta (2018).

Nota-se que os usuários deste tipo de serviços são consumidores que buscam informações da empresa no site, correspondendo a 71,7\%. Esse dado demonstra como a empresa deve se preocupar em manter os seus sites bem desenvolvidos, com informações acessíveis. Foi interessante notar que para 4,1\% dos entrevistados, a sua empresa nem mesmo tem um site. Assim, esse investimento é fundamental para o relacionamento com o cliente.

Conforme Zenone (2010), o e-commerce (Comércio Eletrônico), é uma modalidade de comércio realizado por meio de plataformas eletrônicas, tanto em computadores como por celulares. Por meio da internet, o e-commerce passa a ser um espaço ideal para se desenvolver campanhas de marketing digital e divulgar e vender seu produto e serviço. Deste modo, é um investimento essencial para qualquer empresa que queira explorar o marketing digital.

A próxima questão está relacionada com a questão anterior, uma vez que procura entender como foi a experiência ao acessar o site da empresa operadora. O Gráfico 16 apresenta os resultados. 




Fonte: Pesquisa Direta (2018).

Percebe-se um empate técnico entre o item bom e regular. Apenas 7,4\% definiram como ótimo. Assim, as empresas devem buscar gerir os seus sites de um modo mais eficaz, otimizando a sua qualidade, com informações atualizadas sobre os serviços ofertados, layout moderno e com fácil acessibilidade as informações dos serviço, ofertas e promoções. Isso está relacionado principalmente a clareza de informações, pois isso elucidará qualquer dúvida do cliente, melhorando o relacionamento e contribuindo com a fidelização.

Isso está em consonância com os dizeres de Adolpho (2013), onde menciona a importância de utilizar nessa era digital a divulgação por meio de sites, blogs, e-mail marketing e outros. Entende-se deste modo que a empresa precisa ter uma grande quantidade de "amigos" em sua rede, para melhor divulgar o seu trabalho. Isso é especialmente importante quando for realizar uma prospecção para determinadas campanhas específicas.

Por fim, a última questão está relacionada com a contratação de serviços de banda larga na região do Cariri, por meio do site da empresa. O Gráfico 17 apresenta o resultado.

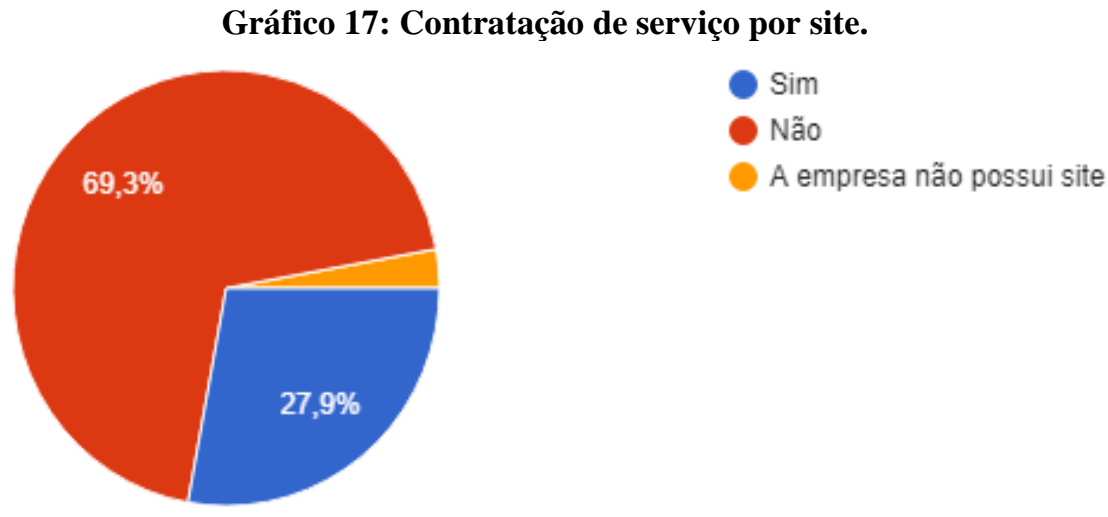

Fonte: Pesquisa Direta (2018). 
Nota-se que dos entrevistados, menos de um terço conseguiu fechar algum pacote de serviços pela internet. Porém, as empresas ainda continuam tendo dificuldade com este canal, uma vez que 69,3\% não conseguiram contratar serviços por meio digital. Assim, as empresas de banda larga na região do cariri, precisam rever os formatados de seus sites e de relacionamento por meio de marketing digital para conseguirem obter êxito em fechar contratos também por meio deste canal.

Zenone (2010), menciona que o uso de sites para vendas é algo que vai ser cada vez mais utilizado pelos consumidores. Consoante a isso, Albertini (2010), aponta a importância deste tipo de comunicação, que juntamente com o surgimento da economia digital o mundo passou a processar as informações de uma forma mais rápida, eficaz e com custo reduzido.

Assim, criar um site com uma eficiente plataforma de venda, tende a ser um meio produtivo de vendas e fechamentos de contratos.

\section{Considerações Finais}

O presente trabalho, por meio de uma revisão de literatura e de uma pesquisa quantitativa, buscou elucidar a importância do uso do marketing digital, estabelecendo o marketing de relacionamento com seu cliente, onde se analisou o seu impacto entre os consumidores de serviços de empresas de telecomunicação e banda larga, na região do Cariri.

Notou-se que na região do Cariri, há várias empresas que atuam no ramo de oferta de serviço de internet em banda larga, oferecendo seus serviços em planos de internet diversificados via fibra óptica, ADSL e rádio, com atrativos adicionais como telefonia fixa e TV por assinatura, criando-se assim grande competitividade.

Percebeu-se que, diante do desenvolvimento tecnológico e da evolução do ambiente digital, se faz relevante que as empresas busquem meios de divulgação mais eficientes, e com menos custos. Deste modo, a utilização de sites e aplicativos, buscando um relacionamento com o cliente, que por meio do e-commerce, ou por meio de redes sociais, é algo importante para a fidelização de clientes.

Entretanto, constatou-se que o sucesso das empresas ao usarem o marketing digital depende de uma série de fatores como: o setor de atuação e o perfil da empresa. Assim, é fundamental que as empresas invistam em inovações gerenciais no seu uso, com o objetivo de produzir ganhos e resultados.

Notou-se também que as redes sociais são um interessante campo de exploração para as empresas, pois, muitas pessoas usam as redes sociais tanto para reencontrar amigos, como para interagir pessoas, atraindo a atenção de anunciantes. Percebeu-se então ser possível por meio das redes sociais, conhecer o público alvo, sabendo quais são os seus desejos e suas necessidades.

Por meio da pesquisa quantitativa, pode-se entender vários fatores referentes a importância do uso de mídias digitais. Por exemplo, algo notório foi que a grande maioria acessa o serviço de internet, 
por meio de banda larga. Assim, esse é um excelente campo de atuação. Destes, a maioria são jovens que utilizam redes sociais, mostrando que as empresas deste segmento devem definir campanhas específicas para esse público.

Outro aspecto relevante é que a maioria dos entrevistados acessam a internet por meio de Smartphones. Assim, as empresas precisam investir em plataformas que deem mais visibilidade de seus produtos, por meio destes dispositivos. Deste modo, o investimento no desenvolvimento de aplicativos pode ser uma excelente alternativa.

Nota-se também, que embora a maioria das pessoas que adquirem serviços de banda larga, o fazem por meio de indicação ou panfletos, há muito campo para o crescimento por meios de divulgação por sites ou por redes sociais. Não se pode desperceber também do potencial do e-commerce, que tem sido um meio de vendas em franco crescimento. Foi interessante compreender também que o fluxo de informações por meio de SMS, WhatsApp é um meio fundamental de se conectar com o cliente.

Assim, tanto para divulgação como para captar informações sobre o público alvo, as redes sociais são muito valiosas. Algumas empresas já perceberam isso, pois, mais da metade das pessoas que possuem internet com banda larga são contatadas por meio desse sistema, muito embora o contato telefônico e por meio de panfletos ainda seja muito utilizado.

Algo digno de nota, é que muitos consumidores ainda pesquisam sobre a reputação da empresa antes de adquirirem seus produtos. Essa tendência revela que as empresas precisam estar atentas e procurar estabelecer uma boa relação com o cliente, por meio das mídias sociais, dando sempre atenção e o bom atendimento.

Compreende-se assim que as empresas devem buscar gerir os seus sites, redes sociais e outras mídias digitais de modo eficaz, otimizando a sua qualidade, com informações atualizadas sobre os serviços ofertados, layout moderno e com fácil acessibilidade às informações dos serviço, ofertas e promoções. Tal aspecto está relacionado principalmente a clareza de informações, pois isso elucidará qualquer dúvida do cliente, melhorando o relacionamento e contribuindo com a fidelização.

Em conclusão, pode-se afirmar que a pesquisa conseguiu atingir seu objetivo geral e objetivos específicos, percebendo que as empresas de banda larga na região do cariri, precisam rever os formatados de seus sites e de relacionamento por meio de marketing digital, redes sociais, e-commerce e outros, para conseguirem obter êxito em fechar contratos otimizando seu marketing de relacionamento.

\section{Referências}

ADOLPHO, C. Os 8 Ps do Marketing Digital: O guia estratégico do Marketing digital. São Paulo: Novatec, 2013. 
ALBERTIN, Alberto L. Comércio eletrônico: modelos, aspectos e contribuições. São Paulo: Atlas, 2010.

ALMEIDA, C. C. Métodos e técnicas de pesquisa. Rio de Janeiro: Saraiva, 2011.

BERGAMASCHI, S.; ALBINO, J. P.; TRIPOLONI, J. M. P.; BARIZON, M. V. F.; SLOBODTICOV, R. Redes sociais na internet: uma investigação sobre práticas de compartilhamento de arquivos no Facebook. In: Rev. Geprós, ano 6, n. 4, out/dez, 2011.

BOGO, K. C. A história da internet. Disponível em: $<w w w$. kplus.com.br/matéria.asp?co=11\&rv=vivencia> Acesso em: 12 de mar. 2018.

CARAVANTES, G. Gestão estratégica de resultados. Porto Alegre, Editora Age, 2004.

COMSCORE. Pesquisa. Disponível em: <http://www.comscore.com/Insights/Presentationsand-Whitepapers/2015/comScore-Shareablee-The-State-of-Social-Media-in-Brazil>. Acesso em 11 de mar. 2018.

COSTA, L. (Coord.). Redes: uma introdução às dinâmicas da conectividade e da autoorganização. Brasília: WWF-Brasil, 2013.

FILIPINI, D. Oportunidades de negócios na Internet. São Paulo: LeBooks, 2014.

GIGLIO, E.M. Comportamento do consumo. $3^{\text {a }}$ Edição, São Paulo, Thomson Editora, 2005.

GIL, A. Como o uso das redes sociais em um país como o Brasil pode agregar valor aos negócios. [2013]. Disponível em: 〈https://endeavor.org.br/os-negocios-e-as-redes-sociais/> Acesso em 15 de mar. 2018.

GIL, A. C. Métodos e Técnicas de Pesquisa Social. 6º Ed. São Paulo. Atlas, 2011.

G1. Brasil tem 116 milhões de pessoas conectadas à internet. 2018. Disponível em: $<$ https://g1.globo.com/economia/tecnologia/noticia/brasil-tem-116-milhoes-de-pessoasconectadas-a-internet-diz-ibge.ghtml > Acesso em 25 de mai. 2018.

JENKINS, H. Cultura da convergência. Trad. Susana Alexandria. São Paulo: Aleph, 2013.

KARSAKLIAN, E. Comportamento do consumidor. 2. ed. São Paulo: Atlas, 2011.

KOTLER, Philip; KELLER, Kevin Lane. Administração de marketing. 12. ed. São Paulo: Pearson Prentice Hall, 2006.

KOTLER, Philip. Administração de marketing: a edição do novo milênio. São Paulo: Prentice Hall, 2012. 
MADRUGA, Roberto. Administração de marketing no mundo contemporâneo. 3 ed. Rio de Janeiro: FGV, 2006.

MIGUEL, P. A. C.; Metodologia de pesquisa em engenharia de produção e gestão de operações. Rio de janeiro; Elsevier, 2010.

POWELL, J. 33 milhões de pessoas em sua rede de contatos: Com criar, influenciar e administrar um negócio de sucesso por meio das redes sociais. São Paulo: Gente, 2010.

RECUERO, R. Redes sociais na internet. Porto Alegre, RS: Sulina, 2011.

SEBRAE. Redes sociais impulsionam pequenos negócios. 2015. Disponível em: <http://revistapegn.globo.com/Empreender/noticia/2015/03/redes-sociais-impulsionampequenos-negocios.html> Acesso em 18 de mar. 2018.

TOMAÉL, M. I.; ALCARÁ, A. R.; CHIARA, I. G. D. Das redes sociais à inovação. Ci. Inf. vol.34 no.2 Brasília May/Aug. 2015.

TORRES, Cláudio. A bíblia do marketing digital. 1ª edição. São Paulo: Novatec, 2009.

TURCHI, Sandra R. Estratégias de marketing digital e e-commerce. São Paulo: Atlas, 2012.

YIN, R. K. Estudo de caso: planejamento e métodos. 4. ed. Porto Alegre: Bookman, 2010.

ZENONE, L. C. Marketing de relacionamento: tecnologia, processos e pessoas. São Paulo: Atlas, 2010.

Como citar este artigo (Formato ABNT):

FERREIRA, Francisco Jurandir; DIAS JÚNIOR, Francisco Demontiez. Marketing Digital em Redes Sociais e E-Commerce: Um Estudo Sobre o Impacto das Campanhas das Empresas de Banda Larga na Região do Cariri. Id on Line Rev.Mult. Psic., 2018, vol.12, n.42, Supl. 1, p. 255-281. ISSN: 19811179 .

Recebido: 05/11/2018;

Aceito: 06/11/2018 


\begin{abstract}
ANEXO I - QUESTIONÁRIO
Tema da Pesquisa: MARKETING DIGITAL EM REDES SOCIAIS E E-COMMERCE - UM ESTUDO SOBRE O IMPACTO DAS CAMPANHAS DAS EMPRESAS DE BANDA LARGA NA REGIÃO DO CARIRI.
\end{abstract}

Prezado Sr. / Sra. obrigada pela sua visita. Responder este breve questionário vai ajudar-nos a obter os melhores resultados no desenvolvimento da pesquisa, na qual o mesmo tem como intuito auxiliar no resultado final do trabalho de conclusão de curso. Onde o objetivo geral analisar o impacto as campanhas de marketing digital via redes sociais e e-commerce, praticadas pelas empresas de banda larga na região do Cariri, podem causar na decisão de compra dos consumidores, trazendo como benefícios, o entendimento da importância do marketing digital e suas nuances para os gestores utilizá-las em prol de seus empreendimentos, melhoramento na aplicação prática de estratégias de marketing digital, inovações na qualidade das ações de marketing digital das empresas da região, colocar em prática ações que seja do real interesse do consumidor e melhorar qualidade do atendimento via plataformas digitais.

Questões:

$1^{\circ}$ Utiliza serviço de Banda larga?

$2^{\circ}$ Sua idade?

$3^{\circ}$ Qual o meio de acesso?

$4^{\circ}$ Como você veio aderir os serviços de banda larga de sua fornecedora ou prestadora?

$5^{\circ}$ Como você avalia atendimento da sua prestadora de banda larga através das plataformas digitais?

$6^{\circ}$ Como a sua fornecedora ou prestadora de serviço de banda larga entra em contato com você?

$7^{\circ}$ Como sua prestadora de serviço banda larga faz divulgação de novos produtos ou serviços?

$8^{\circ}$ Quando você vai aderir um serviço de banda larga, costuma pesquisar nas redes sociais e sites das empresas, promoções, reputação, serviços oferecidos e etc?

$9^{\circ}$ Baseado na pergunta anterior quais as informações você busca nas pesquisas em redes sociais e sites das empresas do serviço de banda larga na intenção em aderir o serviço? $10^{\circ} \mathrm{Em}$ datas especiais como seu aniversário, você recebe alguma notificação de sua prestadora?

$11^{\circ}$ Você já precisou apresentar alguma reclamação contra a empresa prestadora do serviço?

Se sim, qual o meio que você usou para entrar em contato com a empresa?

$12^{\circ}$ Como você classificaria o uso das redes sociais pelas operadoras de banda larga que atuam na região do cariri?

$13^{\circ}$ Você se sente fidelizado pela sua empresa de internet?

$14^{\circ}$ Você já acessou o site da sua empresa provedora de internet?

$15^{\circ}$ Qual a sua experiência ao acessar o site do seu provedor de internet, quanto às informações dos planos ofertados, navegação e acessibilidade?

$16^{\circ}$ Conseguiu contratar algum serviço através do site da sua empresa de internet? 